\title{
Professional care after deliberate self-harm: a qualitative study of young people's experiences
}

This article was published in the following Dove Press journal:

Patient Preference and Adherence

28 January 2015

Number of times this article has been viewed

\author{
Hans Idenfors \\ Gunnar Kullgren \\ Ellinor Salander Renberg \\ Department of Clinical Sciences, \\ Division of Psychiatry, Umeå \\ University, Umeå, Sweden
}

Correspondence: Hans Idenfors Department of Clinical Sciences, Division of Psychiatry, Umeå University, SE-90I 87 Umeå, Sweden

$\mathrm{Tel}+467027 \mathrm{I} 5 \mathrm{I} 10$

Fax +4690 I35324

Email hans.idenfors@umu.se
Background: Deliberate self-harm (DSH) is increasingly common among young people. At the same time, treatment and support after DSH are often hampered by low compliance.

Aim: To explore young people's perceptions of care and support during a 6-month period following their first contact for DSH.

Methods: We conducted nine semistructured interviews with young people aged 16-24 years 6 months after their first contact for DSH. The interviews were analyzed using qualitative content analysis.

Results: Three main themes were extracted from the interviews. "Am I really in good hands?" describes whether the participants felt they were being listened to and taken seriously and whether they could rely on the competence of the professionals and the appropriateness of treatment, including keeping agreements and communication with other relevant agencies. "Help should match life circumstances" comprises how basic practicalities such as travel possibilities affect treatment and concomitant assistance in everyday living. Financial matters and jobseeking were perceived as necessary for optimal treatment and well-being. "Making yourself better" includes participants' efforts to manage on their own, through realizing their own responsibility to be engaged and actively take part in treatment planning.

Conclusion: Flexibility and responsiveness to young people's own views and specific needs in treatment arrangements are of crucial importance. The significance of basic practical help cannot be underestimated and should not be overlooked.

Keywords: young adults, deliberate self-harm, qualitative, treatment experiences

\section{Introduction}

Globally, suicide is a major public health problem and a common cause of death among young people. ${ }^{1}$ This is particularly serious, as there is no decline in suicide rates in this age group, in contrast to other age groups in most countries. ${ }^{2,3}$ One of the most evident risk factors for suicide is deliberate self-harm (DSH), ${ }^{4,5}$ which includes all acts of nonfatal self-inflicted harm, regardless of intent. ${ }^{6} \mathrm{DSH}$ primarily affects young people, ${ }^{7}$ with a prevalence of approximately $10 \% .{ }^{8}$ No single factor can explain why young people deliberately harm themselves. A wide array of risk factors have been identified, including mental disorders, trauma, interpersonal difficulties, low self-esteem, bullying, poor parent-child attachment, concerns about sexual orientation, social isolation, impulsivity, and family history of suicide or self-harm. ${ }^{8}$ Also, hopelessness is an important risk factor ${ }^{8}$ whose severity can have implications for planned treatment. ${ }^{9}$ Self-reported motives for self-harm are a wish to die, to get relief from a terrible state of mind, or to punish oneself. ${ }^{10-12}$

DSH among young people has increased during recent years. ${ }^{2,13,14}$ Several explanations have been suggested, such as increased stress for adolescents, more use of alcohol and drugs, easier access to medication, and social transmission of DSH behavior. ${ }^{8}$ 
DSH entails substantial costs for health services and society, but it is difficult to estimate the direct cost of self-harm, due to its multifaceted nature. The indirect costs are unknown but are likely to be significant, given the high prevalence of DSH in the community. ${ }^{15}$

Guidelines for management of self-harm suggest that treatment should be tailored to individual need. ${ }^{15}$ Associated conditions such as depression and anxiety disorders should be treated with psychological, pharmacological, and psychosocial interventions. ${ }^{15}$ Psychological interventions that are specifically structured to reduce self-harm are recommended, but there is less evidence to support the use of drug treatment. ${ }^{15}$ At the same time, psychiatric care of young people following DSH is hampered by low compliance. Many adolescents never attend psychiatric treatment after DSH, or withdraw from treatment in the first 18 months. ${ }^{16-19}$

In a review examining the effectiveness of clinical interventions designed to reduce the repetition of DSH in adolescents and young adults, ${ }^{20}$ no studies were found to increase adherence to treatment in general. The review concluded that new strategies are needed to promote adherence to aftercare. An intervention by Spirito et $\mathrm{al}^{21}$ using a problem-solving format and aimed at enhancing compliance was effective in increasing treatment adherence, but only when controlled for barriers to service in the community. It is thus evident that there is a need for further studies to better understand mechanisms involved in this poor adherence, as viewed by the young persons themselves.

\section{Aim}

We sought to explore young people's perceptions of care and support during a 6-month period following their first contact for DSH.

\section{Methods}

Given the nature of the subject matter, to best interrogate young people's perspectives, a qualitative research design consisting of interviews, subsequently analyzed by thematic analysis, was used.

\section{Procedure}

Recruitment was carried out from March 2009 to March 2011 at the emergency department, psychiatric emergency services, child and adolescent psychiatry clinic, and a psychiatric ward in a catchment area in northern Sweden. Patients aged 1624 years were eligible for inclusion. Because our aim was to investigate initial experiences of care after DSH, we selected patients with no previous contact with health services due to DSH. To define DSH, we used the International Statistical
Classification of Diseases and Related Health Problems 10th Revision (ICD-10) criteria for intentional self-harm, $\mathrm{X} 60-\mathrm{X} 84,{ }^{22}$ which do not ascribe suicidal intent. Suicidal intent is often difficult to ascertain ${ }^{6}$ and was not within the scope of the present study.

The study was approved by the Regional Ethical Review Board in Umeå, Sweden (Dnr 09-001 M). All participants provided written informed consent prior to the first interview.

\section{Participants}

Medical staff at the recruitment sites identified 17 eligible patients for potential inclusion. It is likely that a number of patients fulfilling the inclusion criteria were missed because of difficulties in reaching out to all units involved, where many of the medical staff may have been unaware of the present study. Five of the patients identified for potential inclusion declined to participate, and two were discharged before they could be approached about participation in the study. Ten patients were recruited for an initial interview. ${ }^{23}$ Six months later, nine of these ten participants took part in a follow-up interview (one woman declined participation), constituting the population for the present study (Table 1). The follow-up interviews were conducted during 2009-2011.

\section{Interviews}

The interview guide focused on experiences of professional care, highlighting shortcomings, positive aspects, and barriers during the 6-month period.

Open-ended questions were used in order to encourage the participants to speak more freely. Unexpected and interesting information that cropped up during the interviews was explored further. ${ }^{24}$ All interviews were conducted by the first author $(\mathrm{HI})$, who is a resident in psychiatry but who was not involved in the care of those he interviewed. The interviews took place at a location chosen by the person to be interviewed: eg, the psychiatric clinic, the participant's home, or outdoors. One participant could only be reached by phone for the interview, a functional solution, as the interviewer had met him at an earlier interview. The interviewer had no access to medical records and obtained all information from the participants. Interview lengths were 22-41 minutes. Interviews were recorded digitally and subsequently transcribed verbatim in Swedish.

\section{Analysis}

Interviews were systematically analyzed with an inductive approach. The analyses were done according to protocol by Graneheim and Lundman, ${ }^{25}$ and Krippendorff, ${ }^{26}$ with the interpretation level of thematic analysis. ${ }^{27}$ The interviews were first read thoroughly to get an overall view and then divided into 
Table I Characteristics of study participants

\begin{tabular}{|c|c|c|c|c|c|}
\hline $\begin{array}{l}\text { Age at DSH, } \\
\text { years }\end{array}$ & Sex & Recruitment source & Type of DSH & Earlier DSH & Treatment since DSH \\
\hline 17 & Male & Emergency department & Self-poisoning & No & Counseling, social services \\
\hline 22 & Male & Emergency department & Self-poisoning & No & Counseling, medicine \\
\hline 17 & Female & Child and adolescent psychiatry & Cutting/attempted jump & No & Counseling, medicine \\
\hline 23 & Female & Psychiatric emergency services & Cutting & Yes, cutting & $\begin{array}{l}\text { Counseling, social services, } \\
\text { medicine, inpatient care }\end{array}$ \\
\hline 17 & Female & Child and adolescent psychiatry & Cutting/self-poisoning & Unknown & Counseling, medicine \\
\hline 21 & Female & Psychiatric emergency services & Cutting & Yes, hitting & Counseling, medicine \\
\hline 20 & Male & Psychiatric emergency services & Cutting/hitting & No & Counseling, medicine \\
\hline 24 & Female & Psychiatric emergency services & Cutting & No & Counseling, medicine \\
\hline 19 & Male & Psychiatric ward & Self-poisoning & Yes, cutting, hitting & Counseling, inpatient care \\
\hline
\end{tabular}

Abbreviation: DSH, deliberate self-harm.

meaning units consisting of words, sentences, or paragraphs related to each other by content and context. Each meaning unit was condensed (shortened) and assigned a code. Based on similarities and dissimilarities, the codes were joined into categories, continuously viewed in relation to the original interview texts. From the underlying meaning in the categories, common themes were constructed. The assignment of codes was performed by the first author, with verification by the last author, and the process of creating categories and themes was conducted by the first and last authors in a series of meetings and discussions. The computer software OpenCode 3.4 (Umeå University, Umeå, Sweden) was used during the analysis. ${ }^{28}$

\section{Results}

Six categories and three themes were created from the codes, presented here. All categories included comments from all or all but one of the participants and were considered as general according to Hill et al's ${ }^{29}$ definition. The participant code number is shown in brackets and is unrelated to the order of participants in Table 1.

\section{Themes}

The following three themes help encapsulate the six categories (Figure 1).

\section{Am I really in good hands?}

This concerns whether participants felt they were listened to and taken seriously, whether they could rely on the competence of the health care professionals, whether appropriate treatment was used, and how well agreements were kept and communication occurred with other relevant parties.

\section{Help should match life circumstances}

This involves practicalities such as transportation and finance, practical help with daily living, finding a job or an apartment, and financial assistance.

\section{Making yourself better}

This includes efforts to manage on one's own, recognizing one's own responsibility to get better and make contacts work, with communication of problems and needs; however, it also includes a desire to be able to influence the intensity and type of treatment received.

\section{Categories \\ Speaking the same language}

Participants described how important it was to have a contact person in whom they had confidence. A precondition for them to speak openly was being listened to in a nonjudgmental manner and being allowed and invited to tell their narrative. Although it was expressed that it could be easier to talk to friends and family - whom they trusted more than professional helpers - it was also described how they could talk to friends about less serious issues and to professionals about more difficult problems.

Participants felt that confiding in people with experiences similar to their own, such as family situations, psychological problems, or health care, was of special importance, as these people could more easily understand their situation.

$[\ldots]$ then there's my classmate who's got the same sort of family situation and that, so we talk a lot and can see ourselves in each other. Perhaps we can't console one another, but I mean we can ... we can still feel we're not alone, that someone understands. (Participant 1)

\section{Having trust in the care of professionals}

Participants felt that if psychiatric staff were unfamiliar with their specific problems, disabilities, or psychiatric history, this could lead to improper and unsuccessful treatment. They also felt that medication was prescribed too easily, without proper evaluation, leading to more medication, higher doses, and a higher degree of insecurity. Careful, considered prescription making was seen as taking the problem seriously. 

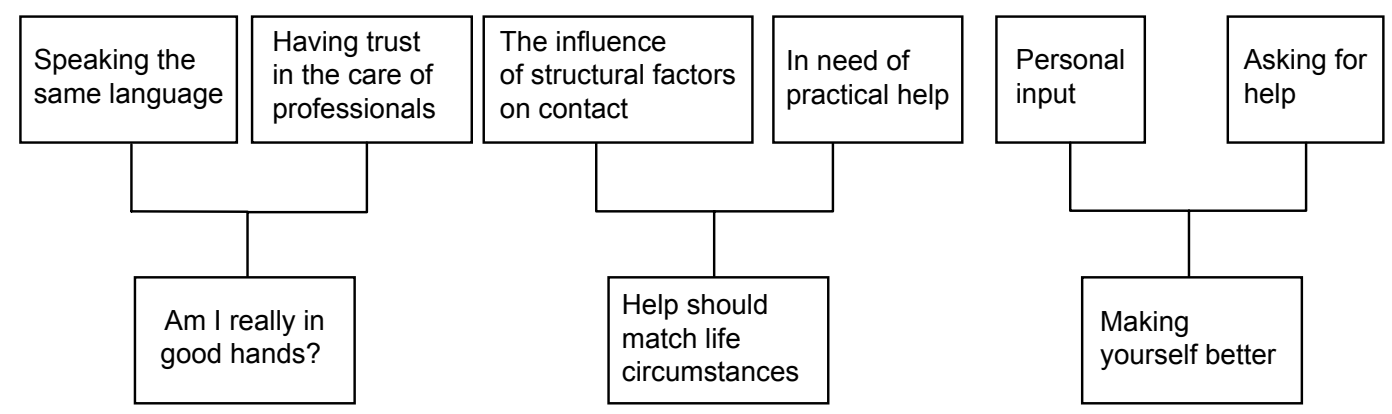

Figure I Categories (top) and themes (bottom) relating to care of patients after deliberate self-harm.

Of course I understand how they look at it - they don't want me to overdose again, so [...] Then it felt like they took you more seriously instead of other doctors who just pumped you full of drugs. (Participant 4)

Participants noted communication problems within the health care system, such as delays in transfers, and between the health care system and other authorities, such as social services. Having no further visits scheduled when waiting for a new contact led to a feeling of abandonment. A formal referral was appreciated, as they felt that making contact on their own was difficult.

Well, I've got a note and an appointment so it hasn't been a problem, it's just getting there on time [...] that I have to call them myself and that I think it's so difficult so, no, I'd rather just not bother. (Participant 5)

Participants experienced how treatment was ended too early, especially bearing in mind their recent episodes of $\mathrm{DSH}$, and how this could lead to adverse outcomes. One interviewee even suspected that her contact was terminated because of an organizational change at the clinic. This made her feel disappointed.

It felt as if there was some, it was their reason for wanting to stop, not mine maybe. (Participant 1)

Participants reported that promises made to them about the effects of medication and waiting times were not fulfilled. This led to mistrust, worry, and a fear of being forgotten. There was a request for more openness on these issues.

Have they forgotten me, like, why is nothing happening and like all the worry which wasn't exactly good which meant more emergency visits at the mobile team. (Participant 6)

The interviewees considered increased self-insight, activation, new coping strategies, and medication to be helpful. They viewed positively having high accessibility and regular contact with health care personnel, with personnel also contacting patients. Shortcomings relating to treatment were lack of long-term treatment, unnecessary meetings, and expectations for patients to find treatment solutions themselves. Medication could increase calm, prevent DSH, and improve well-being, but when such positive effects subsequently diminished, this was viewed as being disappointing. Participants requested more information about experienced side effects of their medication, such as shaking, increased suicidality, and self-harm. One female participant had seizures following abrupt discontinuation of medication.

It would have been good if someone had said how important it is that [...] you sort of gradually reduce. (Participant 6)

\section{The influence of structural factors on contact}

Participants reported that the location of health services and access to public transportation affected the possibility of attending health services. Travel problems included experiencing panic attacks on buses, being unable to use means of transportation without a companion, or lacking a driver's licence. They cited as possible solutions having home visits, assistance in getting to the clinic, and contact by phone. A reminder by phone the day before a visit was also suggested.

Or that they ring like a day before. 'Cause we wrote it in the calendar, but I never look there. (Participant 2)

Health services' cumbersome administrative systems sometimes led to unnecessary extra costs for the participants. Being without money and not knowing that social welfare would cover the cost for medicine could even prevent them from purchasing prescribed antidepressants.

I haven't taken them every day 'cause I haven't had the money to get them. But then I found out that you can get a certificate from the social. You don't have to bring in ... a bunch of receipts after. So I went and got one, and then I could get all my prescription meds in one go. (Participant 7) 
Other structural problems they mentioned were long waits for specific investigations, and that they had to switch contacts because of a change of residence or because they turned 18 .

\section{In need of practical help}

Participants mentioned that having work or attending school was important for everyday structure and interaction with others. They requested more support and even asked to have personnel at home to keep them company. They also asked for more care in terms of inpatient treatment. At the same time, a stay in the psychiatric ward for adults was described as negative by those participants who had been admitted as inpatients, because it could be a confined environment that was difficult to handle.

I can't be shut in like that, I can't handle it. It was like when

I was on remand last year. (Participant 8)

Because of psychological problems, participants also had to move back in with their parents.

So then I decided to, well, live at home basically, 'cause I, it felt like I wasn't ready to move up there [to the place of study] again. (Participant 9)

Family and friends gave support, reduced loneliness, and with their presence prevented self-harm. Family also gave necessary financial aid and helped arrange contact with professionals.

Regarding contact with psychiatric services, participants described as beneficial having help with getting a sick note, finding employment, and practical advice such as a suggestion to lock away knives at home.

They appreciated financial aid, help getting an apartment, and help with household tasks, transportation, recreational interests, and visits to health care services. This type of assistance was often delivered by social services.

Yeah, but, for example ... the furniture I've got here - they helped me with that, and stuff. It's that kind of thing. If I need help with shopping. Yeah. And things like paper and stuff. 'Cause I've got this home insurance and change of address and things like that now. I didn't understand how to fill out the form, so they help me with that - things like that. (Participant 2)

\section{Personal input}

Participants had tried but not succeeded to manage without help from family or professional care, and now requested help to become independent. They were aware of their own responsibility to make treatment work by participating actively, but sometimes old habits could obstruct treatment. Reasons given for not contacting health care staff were worsened mental state, that it felt too demanding, or that it would feel like a defeat. They also recognized how problems could be caused by themselves, such as not taking their antidepressants daily or giving health care staff the number to a broken mobile phone.

I said that ... take my number ... but no way did I think of that I would be without a phone. It wasn't exactly what I was thinking as I lay there hung-over, just wanting to go home and sleep, take some Panadol, stay in bed and rot you know what I mean? - like, that's how I was feeling. (Participant 8)

Participants described how they tried to have an impact on their care by influencing the choice of therapist, when to be admitted, when to end treatment, or speaking up when they felt they were receiving inadequate or inappropriate care. One perceived reason for failed intervention was when treatment proceeded not in line with their apparent needs but according to the opinions or policies of the health services' members.

They also described it as negative when, without their participation, health care staff made contact with other agencies and when parents communicated with teachers at school and health care staff.

I like wanted to know what they were talking about. So I don't understand why they went. Yeah. If everyone could sit and talk ... instead. (Participant 2)

Sometimes, participants did not disclose their problems out of consideration to relatives or fear that too much "negative" information in the journal system would be accessible to other parts of health care. At the same time, there was a wish for someone to uncover their emotional state. One interview person described how it was too easy to pretend that she was feeling fine, which led to a premature discharge. Another participant described that he gradually realized his need to speak to someone about his problems.

I went through a period when I didn't want to talk at all, but I guess it was because of that that I tried to kill myself again - 'cause I didn't talk to anyone, I didn't get out what I really felt but ... As I said, I've matured, so now I can talk about it, but I haven't been able to find anybody, 'cause I don't have a phone number anymore. Makes it kind of difficult. (Participant 8) 


\section{Asking for help}

Participants reported that an initial feeling of not being in need of help could change to an insight that help was necessary. There were requests to talk things through or to be admitted to get proper help. There were also those who thought they did not need psychiatric care during the 6-month period, that although it might suit others, it was not necessary in their case.

It's a good institution for, like, kids who maybe feel bad. I just think I didn't need to go there. (Participant 3)

Participants expressed a wish to have more frequent contact with health care services, especially with their doctor and during periods when they had more thoughts of self-harm. Medication for emergency use was requested but not always prescribed, which discouraged one interview person from seeking acute treatment. Participants preferred to seek acute help from their regular therapist, but it was a problem that they could not know whether he or she was available at such short notice. The desire to manage on one's own was another reason for not seeking immediate help. One participant was reluctant to call psychiatric services, as she did not want to allow herself to be in a position of needing help.

In some way I kind of don't want to let myself end up there again, but now I have really, now it's gone so far that I have been sitting in it so fucking long and it's stupid that I haven't rung 'cause it would be bound to be so much better but, well ... (Participant 5)

\section{Discussion}

The interview persons expressed a variety of views regarding their care related to DSH. Being listened to and taken seriously were a recurrent testimony, as has been highlighted in previous studies..$^{30,31}$ Young people presenting to health care services because of DSH are in a vulnerable position: if they feel ignored at their first contact, it could deter them from keeping subsequent appointments or seeking help in the future. In that sense, the initial contact is crucial for establishing an alliance and avoiding feelings of mistrust.

Competence has been stated as one of the most important professional responsibilities, ${ }^{32}$ highly valued by professionals and patients alike. ${ }^{33}$ According to participants, feeling that health care staff were competent involved various factors, such as the staff's knowledge about disabilities, their ability to manage certain behaviors, read medical records prior to consultation, and prescribe medication properly. These factors are undoubtedly an essential part of professional training and cannot be expected in the care and support from family and friends. Participants also experienced that health care staff made promises they could not keep regarding the effects of medical treatment and waiting times, leading to a feeling of abandonment. Professionalism in balancing information is necessary to prevent staff from making unrealistic promises that could lead to mistrust and disappointment. To be honest in the contact with patients and their families is a professional responsibility. ${ }^{32,33}$

Participants expressed negative consequences of changes in the location for treatment. The efforts invested in establishing the initial contact could explain why a change of contact was deemed undesirable. If the motives for a change were not related to the participant's condition, but rather because of administrative reasons, this negatively influenced their desire to continue the contact/treatment. One such example was the transition from child and adolescent psychiatry to psychiatric services for adults, due to chronological age. This transition has earlier been described as problematic with a high risk for dropping out of treatment, and it has been suggested that services should be more flexible during transition, focusing more on the needs of young people rather than on their chronological age. ${ }^{34}$ The situation calls for specially designed strategies in organizing transfer between child and adolescent psychiatry and psychiatric services for adults.

Participants negatively described inpatient care on a ward for adults, emphasizing in particular the restrictive environment. A previous study found that feelings of being controlled on a ward undermined integrity and self-determination. ${ }^{35}$ Another possible reason for discomfort on the ward could relate to the age of the participants. Teilmann et $\mathrm{al}^{36}$ have shown that many young adults in medical and surgical care feel misplaced on a ward for adults, and that many would prefer to stay on a ward solely for young people. This is probably also valid for psychiatric care. The persons interviewed in the present study expressed a reduced independence when experiencing psychological problems, not feeling as adult as they normally did. This supports the idea of wards designated for young adults, in parallel to already existing outpatient care settings for young people.

Participants expressed a great appreciation of various forms of practical help, often provided by social services. Health care professionals might not be aware of this wish and need for practical help, or as prepared as social services to deliver it. As highlighted in the interviews, problems arise when practical matters interfere with psychiatric treatment. Such problems could even interrupt ongoing treatment, leading to adverse outcomes. It seems essential to provide 
adequate practical help, and if health care services are unable to do that, social services should be involved in the process at an early stage. Help with smaller but nevertheless vital practical issues, such as completing forms, might still be provided by health care staff, in accordance with the needs presented by the participants in the present study.

To address identified transportation problems, participants suggested more use of telephone contact, which could easily be extended to the internet, where a webcam could add visual contact. Online treatment has already been successfully implemented, such as with internet psychotherapy, ${ }^{37}$ where one of its advantages is the convenience of having access to online therapy from a home computer. ${ }^{38}$ Other examples are email counseling that facilitates subsequent face-to-face counseling, as it gives more time for self-reflection and allows patients to be more open about their problems. ${ }^{39}$ Also, mobile phone text counseling has several advantages: it is anonymous, gives control to the young individual, and has high flexibility and accessibility. ${ }^{40}$ The suggestion to use it as an adjunct to face-to-face counseling ${ }^{40}$ conforms with young people's preference for technology if it enhances rather than replaces their regular contacts. ${ }^{41}$ Electronic assessments of self-reported health status using microcomputers or mobile phones in the daily lives of the patients are an area where technology can dramatically improve response rates. ${ }^{42}$ It has been used with young people experiencing self-injurious thoughts and behaviors, and provided new information on how such thoughts and behaviors are experienced in real time. ${ }^{43}$ A greater deal of flexibility also using more technological solutions seems to be fruitful in managing contact with young people.

Another suggestion provided by participants to deal with transportation problems was home visits, which could also be a way of overcoming their hesitation to contact health care services. As mentioned in the interviews, not contacting health care services could be a sign of a deteriorating mental state, with an increased risk of DSH. These findings support those of a previous study, where specialist community-based interventions were desired by patients with repetitive selfharming behavior. ${ }^{44}$

Forgetfulness appeared in the interviews as another reason for missing an outpatient visit. Although it could be argued that health care services cannot use resources by having personnel calling and reminding patients about visits, it is also clear that many patients' mental states could render them unable to manage contact with health care. Smart systems to address this issue are warranted. Automated texting services for appointment reminders is one example of a method that increases the likelihood for patients to attend an appointment. ${ }^{45}$

The pronounced need for practical help among the participants highlights the difficulties in managing everyday life when experiencing psychological problems. The emerging independence of these young individuals was reversed, with an increased need for care by parents and/or professionals. This was also reflected in the importance of having continuous contact until a new contact was established; otherwise, patients felt abandoned. Such a lack of support while waiting for treatment after DSH has earlier been described as problematic, with the occurrence of new episodes of self-harm. ${ }^{46}$ This helplessness was also expressed in the difficulties participants had in actively seeking help on their own and how important a referral was. At the same time, we noted a struggle for independence, with patients endeavoring to manage without help and a wish to prepare for autonomy. This was also reflected in whether and when professional care was considered by the interviewees. Treatments that did not take their opinions into account were often perceived as less effective. This highlights the importance of regular evaluation of ongoing treatment, to be adapted according to the patient's input and experience. Shared decision making is when the patient's preference for treatment is investigated, respected, and adhered to. ${ }^{47}$ When used among young people with mental disorders, it increases engagement with ongoing treatment, ${ }^{48}$ a fact also noted by clinicians. ${ }^{49}$

\section{Methodological considerations}

The aim of this study was not to evaluate the care provided per se but instead to better understand the problem of low adherence from the perspective of young people. Therefore, the results should not be regarded as representing how well care functions but rather how it is experienced by the young people themselves.

The same topics were used in each interview, and areas of interest were explored further, improving confirmability. ${ }^{24}$ In addition, the codes and categories were continuously compared with the original interview texts during the analysis. The use of citations to illustrate key areas, and the process of reaching agreement among the authors during analysis, increases the credibility of the study. Nonetheless, the small sample size limits the study's transferability. Not all patients who were eligible for inclusion became participants, which is a potential source of bias if these patients were to present views different from those included in the study. For these reasons, this study's findings should be interpreted with caution. Future research could examine the issues posed in 
this study with larger samples representing patients from different locations.

\section{Conclusion}

The young people in our study emphasized various aspects of professional care following DSH. They value competent professionals who listen to them and allow them to speak freely. Furthermore, they want to be involved in treatment decisions and to receive sufficient information for making informed choices. Treatment contact should be flexible, with alternatives such as contact by phone and home visits. Participants expressed how critical it is to deal with practical problems in their lives, as these problems significantly affect not only their everyday life but also their treatment. Addressing these issues will lead the way to better treatment of young people who have harmed themselves.

\section{Acknowledgments}

We wish to thank the interviewees for their participation in the study, and the staff at the recruitment sites for their help in finding participants.

\section{Disclosure}

The authors declare no conflicts of interest in this work.

\section{References}

1. Patton GC, Coffey C, Sawyer SM, et al. Global patterns of mortality in young people: a systematic analysis of population health data. Lancet. 2009;374(9693):881-892.

2. Rojas Y, Lundgren F. Avsiktligt Självdestruktiv Handling i Sverige: en Underlagsrapport [Deliberate Self-harm in Sweden: a Report of Basic Data]. Stockholm: Socialstyrelsen [The National Board of Health and Welfare in Sweden]; 2006.

3. Bridge JA, Greenhouse JB, Weldon AH, Campo JV, Kelleher KJ. Suicide trends among youths aged 10 to 19 years in the United States, 1996-2005. JAMA. 2008;300(9):1025-1026.

4. Owens D, Horrocks J, House A. Fatal and non-fatal repetition of selfharm. Systematic review. Br J Psychiatry. 2002;181:193-199.

5. Owens D, House A. General hospital services for deliberate self-harm. Haphazard clinical provision, little research, no central strategy. $J R$ Coll Physicians Lond. 1994;28(4):370-371.

6. Skegg K. Self-harm. Lancet. 2005;366(9495):1471-1483.

7. Hawton K, Bergen H, Casey D, et al. Self-harm in England: a tale of three cities. Multicentre study of self-harm. Soc Psychiatry Psychiatr Epidemiol. 2007;42(7):513-521.

8. Hawton K, Saunders KE, O'Connor RC. Self-harm and suicide in adolescents. Lancet. 2012;379(9834):2373-2382.

9. Pompili M, Innamorati M, Gonda X, et al. Affective temperaments and hopelessness as predictors of health and social functioning in mood disorder patients: a prospective follow-up study. J Affect Disord. 2013;150(2):216-222.

10. Scoliers G, Portzky G, Madge N, et al. Reasons for adolescent deliberate self-harm: a cry of pain and/or a cry for help? Findings from the Child and Adolescent Self-harm in Europe (CASE) study. Soc Psychiatry Psychiatr Epidemiol. 2009;44(8):601-607.

11. Boergers J, Spirito A, Donaldson D. Reasons for adolescent suicide attempts: associations with psychological functioning. J Am Acad Child Adolesc Psychiatry. 1998;37(12):1287-1293.
12. Rodham K, Hawton K, Evans E. Reasons for deliberate self-harm: comparison of self-poisoners and self-cutters in a community sample of adolescents. J Am Acad Child Adolesc Psychiatry. 2004; 43(1):80-87.

13. Beckman K, Dahlin M, Tidemalm D, Runeson B. Drastisk ökning av unga som slutenvårdas efter självskada [Drastic increase of hospitalized young people following self-inflicted injury. Drugs the most frequently used method]. Läkartidningen. 2010;107(7):428-431. Swedish.

14. Nock MK, Borges G, Bromet EJ, Cha CB, Kessler RC, Lee S. Suicide and suicidal behavior. Epidemiol Rev. 2008;30:133-154.

15. National Institute for Health and Care Excellence. Self-harm: Longerterm Management. Leicester: The British Psychological Society; 2012.

16. Spirito A, Plummer B, Gispert M, et al. Adolescent suicide attempts: outcomes at follow-up. Am J Orthopsychiatry. 1992;62(3):464-468.

17. Trautman PD, Stewart N, Morishima A. Are adolescent suicide attempters noncompliant with outpatient care? J Am Acad Child Adolesc Psychiatry. 1993;32(1):89-94.

18. Stewart SE, Manion IG, Davidson S, Cloutier P. Suicidal children and adolescents with first emergency room presentations: predictors of six-month outcome. J Am Acad Child Adolesc Psychiatry. 2001; 40(5):580-587.

19. Groholt B, Ekeberg O. Prognosis after adolescent suicide attempt: mental health, psychiatric treatment, and suicide attempts in a nine-year follow-up study. Suicide Life Threat Behav. 2009;39(2):125-136.

20. Burns J, Dudley M, Hazell P, Patton G. Clinical management of deliberate self-harm in young people: the need for evidence-based approaches to reduce repetition. Aust N Z J Psychiatry. 2005;39(3):121-128.

21. Spirito A, Boergers J, Donaldson D, Bishop D, Lewander W. An intervention trial to improve adherence to community treatment by adolescents after a suicide attempt. J Am Acad Child Adolesc Psychiatry. 2002;41(4):435-442.

22. World Health Organization. International Statistical Classification of Diseases and Related Health Problems: ICD-10. 10th Revision. 2008 ed. Geneva: World Health Organization; 2009. Available from: http://apps.who.int/classifications/icd10/browse/2010/en. Accessed December 18, 2014.

23. Idenfors H, Kullgren G, Salander Renberg E. Professional care as an option prior to self-harm: a qualitative study exploring young people's experiences. Crisis. In press 2014.

24. Patton MQ. Qualitative Research and Evaluation methods. 3rd ed. Thousand Oaks, CA: Sage; 2002.

25. Graneheim UH, Lundman B. Qualitative content analysis in nursing research: concepts, procedures and measures to achieve trustworthiness. Nurse Educ Today. 2004;24(2):105-112.

26. Krippendorff K. Content Analysis: an Introduction to its Methodology. 2nd ed. Thousand Oaks, CA: Sage; 2004.

27. Vaismoradi M, Turunen H, Bondas T. Content analysis and thematic analysis: implications for conducting a qualitative descriptive study. Nurs Health Sci. 2013;15(3):398-405.

28. ICT Services and System Development and Division of Epidemiology and Global Health. OpenCode [computer program] version 3.4. Umeå: Umeå University; 2007. Available from: http://www.phmed. umu.se/english/units/epidemiology/research/open-code/?languageId=1. Accessed January 9, 2015.

29. Hill CE, Knox S, Thompson BJ, Williams EN, Hess SA, Ladany N. Consensual qualitative research: an update. J Couns Psychol. 2005;52(2):196-205.

30. Hunter C, Chantler K, Kapur N, Cooper J. Service user perspectives on psychosocial assessment following self-harm and its impact on further help-seeking: a qualitative study. J Affect Disord. 2013;145: 315-323.

31. Dorer C, Feehan C, Vostanis P, Winkley L. Brief report. The overdose process-adolescents' experience of taking an overdose and their contact with services. $J$ Adolesc. 1999;22(3):413-417.

32. Swick HM. Toward a normative definition of medical professionalism. Acad Med. 2000;75(6):612-616. 
33. Wagner P, Hendrich J, Moseley G, Hudson V. Defining medical professionalism: a qualitative study. Med Educ. 2007;41(3):288-294.

34. Singh SP. Transition of care from child to adult mental health services: the great divide. Curr Opin Psychiatry. 2009;22(4):386-390.

35. Johansson IM, Skarsater I, Danielson E. The meaning of care on a locked acute psychiatric ward: patients' experiences. Nord J Psychiatry. 2009;63(6):501-507.

36. Teilmann G, Hertz PG, Blix C, Boisen KA. Unga patienter på sjukhus kommer i kläm [Young patients in hospitals are pinched into a corner]. Läkartidningen. 2012;109(16):817-820. Swedish.

37. Kessler D, Lewis G, Kaur S, et al. Therapist-delivered Internet psychotherapy for depression in primary care: a randomised controlled trial Lancet. 2009;374(9690):628-634.

38. Beattie A, Shaw A, Kaur S, Kessler D. Primary-care patients' expectations and experiences of online cognitive behavioural therapy for depression: a qualitative study. Health Expect. 2009;12(1):45-59.

39. Dunn K. A qualitative investigation into the online counselling relationship: to meet or not to meet, that is the question. Counselling and Psychotherapy Research. 2012;12(4):316-326.

40. Gibson K, Cartwright C. Young people's experiences of mobile phone text counselling: balancing connection and control. Child Youth Serv Rev. 2014;43:96-104.

41. Lindstrom Johnson S, Tandon SD, Trent M, Jones V, Cheng TL. Use of technology with health care providers: perspectives from urban youth. J Pediatr. 2012;160(6):997-1002.

42. Hufford MR. Special methodological challenges and opportunities in ecological momentary assessment. In: Stone A, Shiffman S, Atienza A, Nebeling L, editors. Science of Real-Time Data Capture: Self-Reports in Health Research. New York: Oxford University Press; 2007:54-75.
43. Nock MK, Prinstein MJ, Sterba SK. Revealing the form and function of self-injurious thoughts and behaviors: a real-time ecological assessment study among adolescents and young adults. $J$ Abnorm Psychol. 2009;118(4):816-827.

44. Hume M, Platt S. Appropriate interventions for the prevention and management of self-harm: a qualitative exploration of service-users views. BMC Public Health. 2007;7:9.

45. Guy R, Hocking J, Wand H, Stott S, Ali H, Kaldor J. How effective are short message service reminders at increasing clinic attendance? A meta-analysis and systematic review. Health Serv Res. 2012;47(2): 614-632.

46. Horrocks J, Hughes J, Martin C, House A, Owens D. Patient Experiences of Hospital Care Following Self-Harm: a Qualitative study: University of Leeds; 2005.

47. Charles C, Gafni A, Whelan T. Shared decision-making in the medical encounter: what does it mean? (or it takes at least two to tango). Soc Sci Med. 1997;44(5):681-692.

48. Simmons MB, Hetrick SE, Jorm AF. Experiences of treatment decision making for young people diagnosed with depressive disorders: a qualitative study in primary care and specialist mental health settings. BMC Psychiatry. 2011;11:194.

49. Simmons MB, Hetrick SE, Jorm AF. Making decisions about treatment for young people diagnosed with depressive disorders: a qualitative study of clinicians' experiences. BMC Psychiatry. 2013;13:335.
Patient Preference and Adherence

\section{Publish your work in this journal}

Patient Preference and Adherence is an international, peer-reviewed, open access journal that focuses on the growing importance of patient preference and adherence throughout the therapeutic continuum. Patient satisfaction, acceptability, quality of life, compliance, persistence and their role in developing new therapeutic modalities and compounds to optimize

\section{Dovepress}

clinical outcomes for existing disease states are major areas of interest for the journal. This journal has been accepted for indexing on PubMed Central. The manuscript management system is completely online and includes a very quick and fair peer-review system, which is all easy to use. Visit http://www. dovepress.com/testimonials.php to read real quotes from published authors. 